\title{
Post-CAR-T Cell Therapy (Consolidation and Relapse): Lymphoma
}

\author{
Didier Blaise and Sabine Fürst
}

Even after a decade of use, CAR-T cell therapy for non-Hodgkin lymphoma (NHL) is still evolving, and disease control is now the main concern in the majority of experienced centres. Indeed, despite highly appealing objective response (OR) rates in refractory patients, the long-term overall survival (OS) of this population has only slightly improved. Pivotal studies have suggested that 2-year OS rates do not surpass $30 \%$, even though results improve when complete response (CR) is achieved within the first 3 months after treatment (Wang et al. 2020; Schuster et al. 2019; Neelapu et al. 2017). Although achieving this exceptionally high level of OR is praiseworthy, similar improvements have not been made regarding OS, and current OS probabilities are not satisfactory. Of course, there are multiple reasons for this; a substantial proportion of patients either do not achieve an initial response or experience progression very soon after treatment, with poor OS (Chow et al. 2019). Both populations present with disease burden or aggressive cancer prior to CAR-T cell therapy, possibly having been referred too late in the course of treatment or waited too long before CAR-T cells were processed for them. Both of these issues have potential solutions, such as more widely publicizing the efficacy of CAR-T cells, which may increase referrals at an earlier stage, and developing methods, which are already being heavily investigated, for shortening the manufacturing process (Rafiq et al. 2020). In the latter case, the use of allogeneic lymphocytes could allow for already prepared cells to be readily used when needed and would most likely be the most efficient strategy as long as the risk of graft-versus host disease is offset (Graham and Jozwik 2018). Thus, achieving CR is a crucial step in increasing OS, as patients with partial response (PR) or stable disease (SD) present with lower OS, while currently, recurrence appears to be rare when CR is maintained for more than 6 months (Komanduri 2021). However, the disease will likely recur in more than

D. Blaise $(\bowtie) \cdot$ S. Fürst

Transplant and Cellular Immunotherapy Program, Department of Hematology, Institute

Paoli-Calmettes, Marseille, France

e-mail: blaised@ipc.unicancer.fr; fursts@ipc.unicancer.fr 
half of patients in the months following treatment, possibly due to issues such as the poor persistence of CAR-T cells (which may not be as crucial as once thought for acute lymphoblastic leukaemia (Komanduri 2021)) or the loss of target antigen expression (which has been regularly documented (Rafiq et al. 2020)). Both of these mechanisms could potentially be used to develop methods that reduce recurrence after CAR-T cell therapy. In fact, the most popular approaches currently being investigated are attempting to either use two CAR-T cell types that each target different antigens or to create CAR-T cell constructs that target either multiple antigens or an antigen other than CD19 (Shah et al. 2020). The concomitant infusion of CAR-T cells with targeted therapies is also being explored in other B-cell malignancies and appears to both increase the CR rate and decrease recurrence (Gauthier et al. 2020). When recurrence does occur, patient OS is rather dismal, and the best remaining option would most likely be inclusion in a clinical trial. If this option is not available, salvage therapy may be attempted, although cytotoxic treatments are extremely limited given that most diseases have been refractory to numerous lines of treatment prior to immunotherapy. A few case reports and studies with a small patient population receiving anti-PD-1 antibodies, ibrutinib, or ImiDs have been reported with largely anecdotal supporting evidence (Byrne et al. 2019). However, even in the case of a new objective response (OR), the subsequent risk of recurrence is substantial and may invite further consolidation with allogeneic haematopoietic stem cell transplantation (Byrne et al. 2019), which has already been performed in patients treated for acute lymphoblastic leukaemia (Hay et al. 2019). However, the efficacy of this strategy remains to be validated in NHL patients in clinical trials. Further supporting evidence, although limited, has recently been reported concerning an additional treatment with CAR-T cells inducing an OR. Of the $21 \mathrm{NHL}$ patients included in the study, the OR rate after the second infusion was $52 \%$ (CR, $n=4$; PR, $n=7$ ), with some durable responses inviting further investigations (Gauthier et al. 2021). Overall, with such poor outcomes after recurrence, current efforts are also focused on predicting the patients most likely to experience disease progression and that are potential candidates for preemptive consolidation therapy, although there is no doubt that patients who do not achieve a rapid CR should be the first candidates. Additionally, immune monitoring should encompass not only CAR-T cell survival but also the detection of circulating tumour DNA (Komanduri 2021) because this could aid in detecting subclinical recurrence and in deciding whether consolidation or maintenance therapy should be administered. However, currently, all these approaches are highly speculative and require further clinical study.

\section{Key Points}

- Relapse after CAR-T cell treatment for NHL is associated with a dismal outcome.

- Presently, there is no consensus on salvage therapy.

- Investigating methods to prevent recurrence is mandatory.

- Inclusion in clinical trials is recommended. 


\section{References}

Byrne M, Oluwole OO, Savani B, et al. Understanding and managing large B cell lymphoma relapses after chimeric antigen receptor $\mathrm{T}$ cell therapy. Biol Blood Marrow Transplant. 2019;25(11):e344-51.

Chow VA, Gopal AK, Maloney DG, et al. Outcomes of patients with large B-cell lymphomas and progressive disease following CD19-specific CAR-T cell therapy. Am J Hematol. 2019;94(8):E209-13.

Gauthier J, Hirayama AV, Purushe J, et al. Feasibility and efficacy of CD19-targeted CAR-T cells with concurrent ibrutinib for CLL after ibrutinib failure. Blood. 2020;135(19):1650-60.

Gauthier J, Bezerra ED, Hirayama AV, et al. Factors associated with outcomes after a second CD19targeted CAR-T cell infusion for refractory B-cell malignancies. Blood. 2021;137(3):323-35.

Graham C, Jozwik A. Pepper a et al allogeneic CAR-T cells: more than ease of access? Cell. 2018;7(10):5.

Hay KA, Gauthier J, Hirayama AV, et al. Factors associated with durable EFS in adult B-cell ALL patients achieving MRD-negative CR after CD19 CAR-T cell therapy. Blood. 2019;133(15):1652-63.

Komanduri KV. Chimeric antigen receptor T-cell therapy in the management of relapsed nonHodgkin lymphoma. J Clin Oncol. 2021;39(5):476-86.

Neelapu SS, Locke FL, Bartlett NL, et al. Axicabtagene ciloleucel CAR-T cell therapy in refractory large B-cell lymphoma. N Engl J Med. 2017;377(26):2531-44.

Rafiq S, Hackett CS, Brentjens RJ. Engineering strategies to overcome the current roadblocks in CAR-T cell therapy. Nat Rev Clin Oncol. 2020;17(3):147-67.

Schuster SJ, Bishop MR, Tam CS, et al. Tisagenlecleucel in adult relapsed or refractory diffuse large B-cell lymphoma. N Engl J Med. 2019;380(1):45-56.

Shah NN, Johnson BD, Schneider D, et al. Bispecific anti-CD20, anti-CD19 CAR-T cells for relapsed B cell malignancies: a phase 1 dose escalation and expansion trial. Nat Med. 2020;26(10):1569-75.

Wang M, Munoz J, Goy A, et al. KTE-X19 CAR-T cell therapy in relapsed or refractory mantlecell lymphoma. N Engl J Med. 2020;382(14):1331-42.

Open Access This chapter is licensed under the terms of the Creative Commons Attribution 4.0 International License (http://creativecommons.org/licenses/by/4.0/), which permits use, sharing, adaptation, distribution and reproduction in any medium or format, as long as you give appropriate credit to the original author(s) and the source, provide a link to the Creative Commons license and indicate if changes were made.

The images or other third party material in this chapter are included in the chapter's Creative Commons license, unless indicated otherwise in a credit line to the material. If material is not included in the chapter's Creative Commons license and your intended use is not permitted by statutory regulation or exceeds the permitted use, you will need to obtain permission directly from the copyright holder.

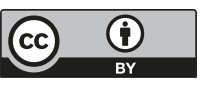

